\title{
- A importância do "Programa de Controle da Raiva" implantado no município de São Paulo, Brasil: aspectos econômicos e de saúde pública
}

* Centro de Controle de Zoonoses de São Paulo Secretaria Municipal de Saúde de São Paulo. Rua Santa Eulalia, 86 CEP 02031-020 São Paulo - SP

\section{- The importance of the "Program of Control of the Rabies" implanted in the municipal district of São Paulo, Brazil: economical aspects and of public bealth}

\author{
* Pedro Melguizo Ramos-CRMV-SPn 0654 \\ ** Pedro Silva Ramos-CRMV-SP n ${ }^{0} 11747$ \\ * Médico Veterinário do Centro de Controle de Zoonoses de São Paulo ( CCZ ) \\ e Coordenador do Programa de Prevenção da Raiva em Humanos do Centro \\ para Organização da Atenção a Saúde (COAS ) \\ ** Médico Veterinário Autônomo
}

\section{RESUMO}

Após o controle da raiva no Município de São Paulo ocorreu uma drástica queda das indicações de tratamentos preventivos para raiva em humanos, que a partir de 1986 apresentam a média de $10.5 \%$. Este trabalho avalia a economia observada com esta redução de tratamentos.

Unitermos: tratamento anti-rábico, vacinação, soro-vacinação.

\section{Introdução}

A raiva é uma das zoonoses mais importantes, pois causa grandes prejuízos à pecuária e à saúde pública na América Latina, constituindo-se em uma das prioridades da Organização Mundial de Saúde, que somente em 1996 estimou terem ocorridas no mundo, entre 35.000 a 50.000 mortes em humanos ${ }^{8}$.

A raiva em saúde pública é sempre relacionada à alta letalidade, mas devemos também levarmos em conta as conseqüências econômicas e sociais, o grande impacto psíquico e emocional devido à ansiedade e ao sofrimento das pessoas agredidas por animais pelo temor de contrair essa doença ${ }^{1}$. Outro aspecto importante a ser considerado são os dias de trabalho perdidos pelas pes- soas durante o transcorrer do tratamento preventivo antirábico.

Segundo a Organização Pan-americana de Saúde (OPS/OMS), no período de 1990 a 1993 na América Latina, foram notificados, em média, 719.442 acidentes por ano, ou seja, 1 acidente para cada 641 habitantes ${ }^{4}$.

No Brasil, segundo a Coordenadoria de Controle de Zoonoses e Animais Peçonhentos do Ministério da Saúde (CCZAP / FNS/MS), em 1996 foram atendidas 392.506 vítimas de acidentes com animais, ou seja, 1 acidente para cada 400 habitantes ${ }^{3}$.

Neste mesmo ano, no Estado de São Paulo, esse índice foi de 1 acidente para cada 414 habitantes $^{3}$ e no Município de São Paulo, foi de 1 acidente para cada 423 habitantes. 
RAMOS, P. M.; RAMOS, P.S. A importância do "Programa de Controle da Raiva" implantado no município de São Paulo, Brasil: aspectos econômicos e de saúde pública. Revista de Educação Continuada do CRMV-SP / Continuous Education Journal CRMV-SP, São Paulo, volume 2, fascículo 2, p. 085 - 088 , 1999.

No Brasil, no período de 1986 a 1997, foram notificados 546 casos de raiva em humanos e atendidas 4.113.961 pessoas envolvidas em acidentes com animais, das quais 2.059 .985 pessoas receberam a indicação de tratamento profilático contra a raiva; portanto um índice de indicação de tratamento de 50,07 \% ${ }^{3}$.

No Município de São Paulo, após 15 anos de intensos trabalhos (1968 a 1983), alcançou-se o controle epidemiológico de raiva: não se verifica a ocorrência de casos de raiva em humanos desde 1982, e em cães e gatos, desde 1984.

Atingindo o controle epidemiológico, as indicações de tratamento para pessoas envolvidas em acidentes com animais decresceram para $37,6 \%$ e $23,5 \%$ em 1984 e 1985, inferiores à média de mais de 50\% observadas no Estado de São Paulo e nos demais estados brasileiros, inclusive da região sul, onde inexistem referências de raiva humana, canina e felina por período de tempo mais prolongado $^{3}$.

A partir de 1984 foram integrados os serviços médico de atendimento ambulatorial e de saúde pública veterinária, assim como aprimorados os sistemas de registro de informações e de identificação do animal que provocou o acidente, oferecendo maior segurança para a dispensa de tratamentos das pessoas envolvidas com esta modalidade de acidente. Essas medidas resultaram em uma significante redução nas indicações de tratamentos anti-rábicos em humanos, mantido nesses últimos 12 anos ao redor de 10,5 \% (1986 a 1997).

\section{Objetivo}

O objetivo deste trabalho é o de avaliar a economia observada com a redução de indicações de tratamentos a pessoas envolvidas em acidentes com animais, após alcançado o controle epidemiológico da raiva no Município de São Paulo.

\section{Materiais e Métodos}

A meta do Programa de Prevenção da Raiva em Humanos no Município de São Paulo é atender a $100 \%$ das pessoas envolvidas em acidentes com animais , meta esta, até então, de difícil avaliação.

As pessoas envolvidas em acidentes com animais são atendidas em uma das 10 Unidades Médicas da Secretaria Municipal de Saúde, que integram o Programa de Prevenção da Raiva em Humanos.

Essas Unidades Médicas têm funcionamento ininterrupto 24 horas por dia, e se localizam em diferentes regiões do Município de São Paulo, possuindo suporte médi- co para atendimento de eventuais reações adversas à terapia com soro ou vacina.

No Município de São Paulo, os cães e gatos são responsáveis por $94 \%$ das agressões ${ }^{5}$, e quando identificados, poderão ser observados clinicamente por 10 dias, e, desde que não apresentem suspeita de terem transmitido o vírus rábico à vítima, possibilitam, com segurança, a dispensa de tratamento preventivo para essa doença ${ }^{6}$.

No tratamento anti-rábico é utilizada a vacina de vírus inativado, Fluenzalida-Palácios, obedecendo a seguinte esquematização: 1 dose diária durante 7 dias; mais 2 doses de reforço, uma das quais no $10^{\circ}$ dia e a outra no $20^{\circ}$ dia após a última dose da série, nos acidente leves. Nos acidentes considerados graves, é indicada a soro-vacinação: no $1^{\circ}$ dia de tratamento, aplica-se soro hiperimune eqüino (40UI/Kg de peso - dose máxima 3.000 UI), e 1 dose diária de vacina durante 10 dias, mais 3 doses de reforço no $10^{\circ}, 20^{\circ}$ e $30^{\circ}$ dias após a última dose da série ${ }^{2,5}$.

No Brasil, com exceção do Município de São Paulo, nos acidentes graves com agressões por cães e gatos, durante o período de observação são indicadas 3 doses de vacina $\left(1^{\circ}, 3^{\circ} \text { e } 5^{\circ} \text { dias }\right)^{2}, 6$.

Para cada atendimento de pessoa agredida por animal, é preenchida uma ficha de vigilância epidemiológica específica denominada "Ficha de Investigação de Acidentes com Animais", onde são anotados dados da vítima (nome, idade, sexo, endereço, telefone, etc.), do animal agressor (espécie, condições, domiciliação, vacinação contra a raiva etc.), e do seu proprietário, do acidente (data, local, causa e tipo), lesões (sede, características, gravidade), o histórico, as condutas médica e médico veterinária, termo de responsabilidade a ser assinado pela vítima, resultado e acompanhamento do tratamento quando realizado.

Pela análise dessas fichas, levantou-se o número de pessoas atendidas e os tratamentos indicados, a cada ano, no período de 1984 a 1997, e como calculou-se a economia com a redução do número de tratamentos.

\section{Resultados e Discussão}

No Quadro 1, constam anualmente o número de pessoas atendidas na rede municipal de saúde (Município de São Paulo), as quantidades de tratamentos indicados e seu percentual, no período compreendido entre 1984 a 1997.

No Gráfico 1, estão ilustradas as quedas nos índices de indicações de tratamentos e a pequena variação anual destes índices ocorrida a partir de 1986.

No Município de São Paulo, de 01 de janeiro de 1986 a 31 dezembro de 1997, foram atendidas 175.935 pessoas envolvidas em acidentes com animais nas Unidades Médicas que integram o Programa de Prevenção 
Quadro 1 - Pessoas atendidas e tratamentos indicados, na rede Municipal de Saúde, em São Paulo, no período de 1984 a 1997.

\begin{tabular}{|c|c|c|c|}
\hline ANO & $\begin{array}{c}\text { PESSOAS } \\
\text { ATENDIDAS }\end{array}$ & $\begin{array}{c}\text { TRATAMENTOS } \\
\text { INDICADOS }\end{array}$ & $\begin{array}{c}\text { \% DE INDICAÇÃO } \\
\text { DE TRATAMENTO }\end{array}$ \\
\hline 1984 & 18.810 & 7.073 & 37,60 \\
1985 & 16.662 & 3.917 & 23,06 \\
1986 & 15.702 & 1.648 & 10,50 \\
1987 & 16.498 & 1.646 & 9,98 \\
1988 & 14.220 & 1.433 & 10,08 \\
1989 & 14.210 & 1.324 & 9,32 \\
1990 & 13.764 & 1.447 & 10,51 \\
1991 & 13.866 & 1.445 & 10,42 \\
1992 & 13.215 & 1.372 & 10,38 \\
1993 & 13.158 & 1.411 & 10,72 \\
1994 & 13.304 & 1.725 & 12,97 \\
1995 & 13.548 & 1.334 & 9,85 \\
1996 & 15.195 & 1.651 & 10,86 \\
1997 & 19.235 & 2.028 & 10,54 \\
\hline TOTAL & 211.387 & 29.454 & - \\
\hline
\end{tabular}

de Raiva Humana. Dentre o total de atendidos, foi indicado tratamento a 18.464 pessoas, correspondendo a $10,5 \%$ do total.

A redução do número de tratamentos, baseada em fundamentação sólida e cientificamente comprovada $1,2,6$, apresenta uma importância ampla, pois, permeia aspectos de:

- menores riscos de reações adversas aos imunobiológicos utilizados;

- economia de insumos nos trabalhos de rotina, como seringas, agulhas e outros;

- racionalização das atividades médicas e paramédicas, pelo melhor aproveitamento do trabalho dos profissionais e dos auxiliares de uma unidade de saúde que podem dedicar-se a várias outras ocorrências com maior disponibilidade de tempo;

- valorização individual e social refletidas pela economia e maior produtividade representadas pela diminuição das ausências no trabalho ou às escolas.

Para avaliação do retorno econômico no período de 1986 a 1997, a título de exemplo, pode-se considerar:

a) 175.935 atendimentos e $10,5 \%$ de indicações de tratamento representaram 18.473 tratamentos indicados;

b) 175.935 atendimentos e $50 \%$ de indicações de tratamentos representam 87.968 tratamentos indicados;

c) 69.495 tratamentos representam a diferença entre os dois percentuais acima considerados, que podem ser designados tratamento poupados ou economizados.

Considerando-se que, em cerca de $10 \%$ dos tratamentos indicados, o esquema seja o de soro-vacinação (uso de soro anti-rábico e 13 doses de vacina contra raiva) e, portanto, em $90 \%$ das indicações o esquema seria o de vacinação, ou seja, o de 9 doses, os 69.495 tratamentos poupados resultam em:

a) $10 \%$ de indicações para soro-vacinação correspondem a 6.949 tratamentos com 13 doses de vacina contra a raiva, totalizando 90.337 doses;

b) $90 \%$ de indicações para tratamento pelo esquema de vacinas correspondem a 62.546 tratamentos com 9 doses e um total de 562.914 doses;

c) o total de doses de vacina contra raiva, relativas aqueles tratamentos, corresponde a 653.251 doses poupadas.

Além das doses de vacina contra raiva, foram poupadas iguais quantidades de seringas, agulhas, além de outros itens de difícil mensuração, como algodão, antisépticos e outros materiais de consumo. Também, devem ser computadas as horas de serviço das equipes médicas e paramédicas.

A partir dos valores acima referidos, é possível estimar-se a economia representada pelos dias de faltas ao trabalho que ocorreriam se as pessoas tivessem sido submetidas aos tratamentos indicados.

A fim de se converter o total de 653.251 doses de vacina não aplicadas em um valor equivalente a dias de trabalho, pode-se considerar:

a) As 69.495 vítimas compareceram às Unidades Médicas e despenderam apenas 1 dia, trabalhando normalmente os outros 12 dias, nos casos de soro-vacinação, ou 8 dias, nos casos de vacinação;

b) soro-vacinações : 6.949 tratamentos, com 12 dias poupados, correspondendo a um total de 83.388 dias;

c) vacinações : 62.546 tratamentos, com 8 dias poupados, correspondendo a um total de 500.368 dias;

d) o total de dias poupados foi de 583.756 dias.

É necessário que se leve em conta que, cerca de um terço das pessoas que se envolvem em acidentes com animais, são crianças com idade até 12 anos, e que necessitam de um adulto que as acompanhe às Unidades Médicas, o que corresponderia a um terço dos 583.756 dias poupados, ou seja, 194.585 dias poupados para acompanhamento a menores de idade. O total de dias efetivamente economizados foi de 778.341 .

Aos valores aqui mencionados, deveriam, ainda serem computados mais alguns, como as despesas de transporte, tratamentos complementares e outros que, entretanto, são de difícil apuração.

\section{Conclusão}

O que se pretendeu foi demonstrar às autoridades públicas que os investimentos na área da saúde pública, 
RAMOS, P. M.; RAMOS, P.S. A importância do "Programa de Controle da Raiva" implantado no município de São Paulo, Brasil: aspectos econômicos e de saúde pública. Revista de Educação Continuada do CRMV-SP / Continuous Education Journal CRMV-SP, São Paulo, volume 2, fascículo 2, p. 085 - 088 , 1999.

priorizando as ações preGráfico 1 - Indicação de Tratamento Preventivo Anti-Rábico, em Humanos, ventivas, representam um importante progresso social e uma significante melhoria na qualidade de vida de uma comunidade.

Entretanto, os profissionais que atuam no controle da raiva não devem ainda se dar por satisfeitos, porquanto considerarem que, aplicando valores anuais da ordem de $1,0 \%$ na redução de indicações de tratamentos para prevenção da raiva humana, contribuíram para a dispensa de uso de 1.383 doses de vacina Município de São Paulo, período: 1984 a 1997.

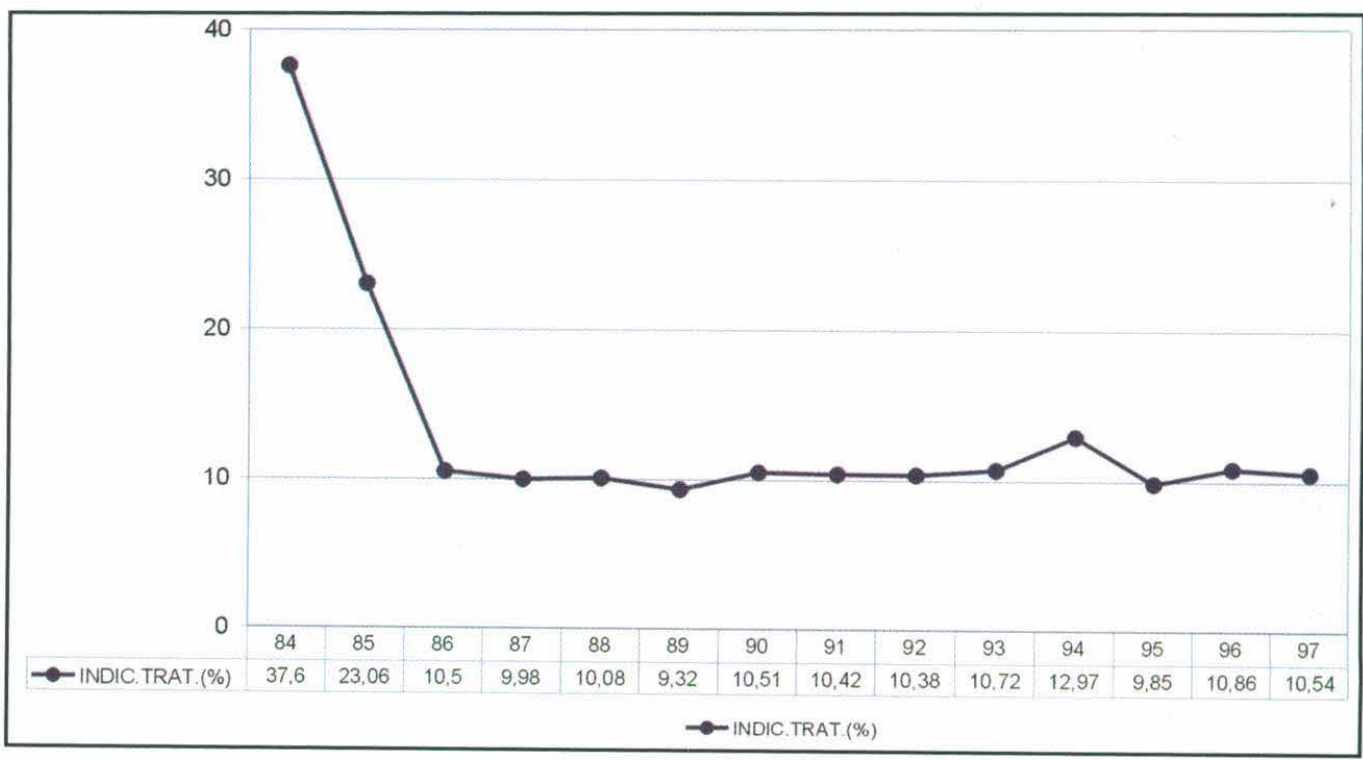

contra a raiva, de igual quantidade de diversos materiais e, principalmente, na economia de 1.648 dias de trabalho

ou 4,5 anos produtivos para as pessoas e para a sociedade, neste período, no Município de São Paulo.

\section{SUMMARY}

After the control of the rabies in the Municipal district of São Paulo happened a drastic fall of the indications of preventive treatments for rabies in humans, that starting from 1986 present the average of $10.5 \%$. This work evaluates the economy observed with this reduction of treatments.

Uniterms: rabies treatment, vaccination, serum-vaccination.

\section{REFERÊNCIAS BIBLIOGRÁFICAS}

1 - ACHA, P. N; SZYFRES, B. Zoonosis y enfermedades transmissibles comunes al hombre y a los animales. Washington: Organizacion Panamericana de la Salud. 2 ed., p.502-26, 1986.

2 - BRASIL. Ministério da Saúde. Centro Nacional de Epidemiologia. Coordenação de Controle de Zoonoses e Animais Peçonhentos. Norma técnica de tratamento profilático anti-rábico humano. 2 ed. Brasília, 1995

3 - BRASIL. Ministério da Saúde. Centro Nacional de Epidemiologia. Coordenação de Controle de Zoonoses e Animais Peçonhentos. Relatório Anual de 1997, 2 ed. Brasília, 1998.

4 - ORgAnización mUNDIAL DE LA SALUd. Analisis de situación de la rabia en America Latina. In: REUNION INTERAMERICANA DE SALUD ANIMAL A NIVEL MINISTERIAL, 11. Washington: OPS, 1995.
5 - RAMOS, P. M. Censo de animales agressores, segun las espécies, en el Município de São Paulo, Brazil, en el período de 1988 a 1997. In: INTERNACIONAL MEETING ON RESEARCH ADVANCES AND RABIES CONTROL IN THE AMERICAS. Puerto Vallarta, México, 1998, p.19.

6 - SÃO PAUlO (Cidade). Secretaria Municipal de Saúde. Norma técnica de profilaxia da raiva em humanos. Diário Oficial do Município, 16/09/1994.

7 - SÃO PAUlo (Cidade). Secretaria Municipal de Saúde. Programa de prevenção da raiva em humanos. Diário Oficial do Município, 09/06/1994.

8 - WORLD HEALTH ORGANIZATION. Division of Emerging and Other Communicable Diseases. Surveillance and Control. World survey of rabies for the year 1996. Geneve, v.32, p.3, 1996. 